\title{
Clinical characteristics of pain in patients with pituitary adenomas
}

\author{
C Dimopoulou', A P Athanasoulia ${ }^{1,3}$, E Hanisch ${ }^{1}$, S Held', T Sprenger ${ }^{2,4,5}$, T R Toelle², \\ J Roemmler-Zehrer ${ }^{3}$, J Schopohl ${ }^{3}$, G K Stalla ${ }^{1}$ and C Sievers ${ }^{1}$ \\ ${ }^{1}$ Department of Endocrinology, Max Planck Institute of Psychiatry, Kraepelinstrasse 2-10, 80804 Munich, Germany, \\ ${ }^{2}$ Department of Neurology, Technische Universität München, Munich, Germany, ${ }^{3}$ Medizinische Klinik und Poliklinik \\ IV, Ludwig-Maximilians-University, Munich, Germany, ${ }^{4}$ Department of Neurology, University Hospital Basel, Basel, \\ Switzerland and ${ }^{5}$ Division of Neuroradiology, Department of Radiology, University Hospital Basel, Basel, \\ Switzerland
}

\author{
Correspondence \\ should be addressed \\ to C Sievers \\ Email \\ csievers@mpipsykl.mpg.de
}

Abstract

Objective: Clinical presentation of pituitary adenomas frequently involves pain, particularly headache, due to structural and functional properties of the tumour. Our aim was to investigate the clinical characteristics of pain in a large cohort of patients with pituitary disease.

Design: In a cross-sectional study, we assessed 278 patients with pituitary disease ( $n=81$ acromegaly; $n=45$ Cushing's disease; $n=92$ prolactinoma; $n=60$ non-functioning pituitary adenoma).

Methods: Pain was studied using validated questionnaires to screen for nociceptive vs neuropathic pain components (painDETECT), determine pain severity, quality, duration and location (German pain questionnaire) and to assess the impact of pain on disability (migraine disability assessment, MIDAS) and quality of life (QoL).

Results: We recorded a high prevalence of bodily pain $(n=180,65 \%)$ and headache $(n=178,64 \%)$; adrenocorticotropic adenomas were most frequently associated with pain $(n=34,76 \%)$. Headache was equally frequent in patients with macroand microadenomas (68 vs $60 \% ; P=0.266$ ). According to painDETECT, the majority of the patients had a nociceptive pain component $(n=193,80 \%)$. Despite high prevalence of headache, $72 \%$ reported little or no headache-related disability (MIDAS). Modifiable factors including tumour size, genetic predisposition, previous surgery, irradiation or medical therapy did not have significant impact neither on neuropathic pain components (painDETECT) nor on headache-related disability (MIDAS). Neuropathic pain and pain-related disability correlated significantly with depression and impaired QoL. Conclusions: Pain appears to be a frequent problem in pituitary disease. The data suggest that pain should be integrated in the diagnostic and therapeutic work-up of patients with pituitary disease in order to treat them appropriately and improve their QoL.

\section{Introduction}

The clinical presentation of pituitary adenomas such as acromegaly, Cushing's disease (CD), prolactinomas and non-functioning pituitary adenomas (NFPA) involves pain, particularly headache, in more than one-third of all patients, probably due to both structural and functional properties of the tumour (1). Mechanical, biochemical, vascular and biopsychosocial aspects, and also a genetic predisposition for primary headache might be involved in the pathogenesis of headache in pituitary disease (1). Among functional pituitary tumours, growth hormone (GH)-secreting adenomas and prolactinomas have been specifically associated with headache, possibly mediated by the change in endocrine status rather than the pituitary mass per se (2). Transsphenoidal surgery may

Published by Bioscientifica Ltd 
lead to significant improvement in headache in patients with non-secreting and hypersecretory pituitary microadenomas (3).

Besides one study on headache in patients with pituitary adenomas (4), systematic studies on pain in patients with pituitary adenomas are still lacking. In acromegaly, GH excess leads to persisting joint-related complaints such as arthropathy and arthralgia (5). On the other hand, both animal models and clinical studies have documented hypothalamo-pituitary-adrenal axis dysfunction as a potential contributing factor to the development of chronic pain via stress mechanisms, allowing potential association with a hypercortisolaemic state in CD (6). However, this has not been systemically investigated so far.

Several studies have documented the frequent comorbidity of depression and impaired quality of life (QoL) in patients suffering from chronic pain. Bair et al. (7) demonstrated more severe pain, greater disability, and poorer health-related QoL in patients with chronic pain suffering from depression and anxiety. The association between neuropsychiatric comorbidities and pituitary disease is well established. Patients with CD are frequently affected by major psychiatric disorders such as depression, anxiety and psychosis, even after long-term biochemical cure of the disease $(8,9)$. Besides, there is an increased prevalence of affective disorders or anxiety-associated personality traits in patients with acromegaly and prolactinomas $(10,11)$. Interestingly, patients with NFPA exhibited a comparable personality pattern, potentially as a result of the pituitary lesion and/or associated hormonal dysregulations (12).

Furthermore, impaired QoL is a common finding in patients with pituitary adenomas (13). In acromegaly, decreased QoL seems to persist despite long-term cure of $\mathrm{GH}$ excess (14). In CD, biochemical remission does not prevent the patients from experiencing a considerable decrease in QoL with physical and psychosocial impairments, especially in the presence of hypopituitarism (15). Female patients with microprolactinomas present with impaired QoL, mostly due to anxiety and depression, while impaired QoL inversely correlates with prolactin (PRL) levels $(16,17)$.

The aim of this study was to describe the clinical characteristics of pain including the following aspects: primary site of perceived pain, quality of pain, nociceptive vs neuropathic pain components, side shift, severity/ intensity, frequency and duration, other associated symptoms, trigger factors of pain, family history in relationship with pain as well as pain-alleviating factors in patients with pituitary adenomas and how these might be influenced by modifiable factors such as tumour and treatment characteristics. We also assessed the role of pain on disability and QoL.

\section{Subjects and methods}

\section{Patients}

In this cross-sectional study, we assessed 278 patients with pituitary adenoma ( $n=206$ from the Max Planck Institute of Psychiatry and $n=72$ from the Ludwig Maximilians University) referred to our endocrinological specialty clinics between 1990 and 2012: 81 patients with acromegaly, 45 patients with $\mathrm{CD}, 92$ patients with prolactinoma and 60 patients with NFPA. The study was approved by the local ethical committee, and all subjects gave their written informed consent.

The study was conducted on average $10 \pm 1$ years after surgery for acromegaly, and $11 \pm 7$ and $13 \pm 8$ years after initial diagnosis of prolactinoma and NFPA respectively. Mean time after CD remission was $7 \pm 3$ years.

\section{Assessment of pain}

'German pain questionnaire' - The 'Germanpainquestionnaire version 1' (GPQ), developed by the German Chapter of the International Association for the Study of Pain, comprises demographic data, phenotypic characteristics, associated symptoms, affective and sensory qualities of pain, pain-relieving and -intensifying factors, previous pain treatment, pain-related disability, a depression scale (CES-D), comorbidities, social factors and health-related QoL (SF-36) (18).

painDETECT - The reliability of the painDETECT questionnaire, developed as a screening tool to identify neuropathic pain components, has been confirmed in several studies $(19,20)$. Following cut-offs have been suggested for screening purposes: score $\leq 12$ (neuropathic component unlikely) and $\geq 19$ (neuropathic component likely); score 13-18 (uncertain, neuropathic pain component possible).

Migraine disability assessment - The migraine disability assessment (MIDAS) questionnaire was designed to quantify headache-related disability over the past 3 months (21) (sum of missed work, school, household chores or non-work activity days, where productivity was reduced by $\geq 50 \%$ ). Headache-related disability can be classified 
into 'little or no disability' (Grade I), 'mild disability' (Grade II), 'moderate disability' (Grade III) and 'severe disability' (Grade IV).

\section{Assessment of QoL}

EQ-5D (EQ visual analogue scale) - The EuroQOL (EQ5D) questionnaire, developed from the EuroQoL group, is a standardised health-related QoL instrument. It consists of five dimensions (mobility, self-care, usual activities, pain/discomfort and anxiety/depression) and the EQ visual analogue scale (EQ-VAS). Each dimension has three levels (no problems, some problems, extreme problems) (22).

\section{Assessment of depression}

Beck Depression Inventory - The Beck Depression Inventory (BDI) is one of the most widely used instruments for measuring severity of depression (23). It comprises 21 questions with at least four possible answer choices about how the patient has been feeling in the last week. A total score of 0-9 indicates minimal, a score of 10-18 mild, a score of 19-29 moderate and a score of 30-63 severe depression (24).

\section{Assessment of comorbidities, biochemical variables and tumour characteristics}

Clinical characteristics were assessed via interview, physical examination and laboratory analyses. Tumour characteristics were determined by thin-section magnetic resonance imaging $(2 \mathrm{~mm})$ of the pituitary. Visual field defects were confirmed by Goldmann perimetry. Details on treatment history, comorbidities, past medical history and actual symptoms were collected from patients' charts. Patients were treated according to the consensus treatment guidelines for the respective pituitary disease.

Biochemical control of acromegaly was defined as: (i) GH below $1 \mu \mathrm{g} / \mathrm{l}$ during a 2-h glucose tolerance test and (ii) insulin-like growth factor1 (IGF1) within two s.D.s of an age- and gender-adjusted normative range (25). Biochemical control of CD was defined as (i) urinary free cortisol values within the assay-specific normal range and (ii) serum cortisol $\leq 1.8 \mathrm{~g} / \mathrm{dl}(50 \mathrm{nmol} / \mathrm{l})$ after $1 \mathrm{mg}$ dexamethasone (26). Normoprolactinaemia was defined as PRL of $\leq 25 \mathrm{ng} / \mathrm{ml}$ for women and $\leq 20 \mathrm{ng} / \mathrm{ml}$ for men.

Evaluation of pituitary function comprised basal fasting measurements of IGF1, thyrotrophin, free thyroxine, total triiodothyronine, gonadotropins, PRL and testosterone (in men) or oestradiol (in women) and an insulin tolerance test, in the case of suspected corticotroph or somatotroph pituitary deficiency.

\section{Medical treatment}

Use of analgesics comprised non-steroidal antiinflammatory agents (19\%) and opioid analgesics (5\%). Dopamine agonists were applied due to pituitary disease in 123 cases. Patients with secondary hypoadrenalism, hypothyroidism, hypogonadism and hyposomatotropism were studied while on optimised replacement therapy. Antidepressant therapy was not recorded.

\section{Statistical analyses}

Statistical analysis was performed using PASW Statistics (formerly SPSS) Version 18 for Windows. Sample characteristics were compared using $\chi^{2}$ tests and ANOVA. Differences in pain characteristics between patients with different forms of pituitary disease were evaluated with an analysis of covariance (ANCOVA) controlling for age, gender, BMI and tumour size, characteristics that differed between the four groups. In the case of group differences, post hoc tests, corrected for multiple comparisons following the Bonferroni-Holm procedure, were applied. Correlation of pain with QoL and depression in the whole group of patients with pituitary adenomas and within the subgroups was performed using Pearson's correlation coefficient. A $P$ value of $<0.05$ was considered statistically significant.

\section{Results}

\section{Patient demographics}

Of the 278 pituitary adenoma patients included, 170 were female (61\%) and 108 were male (39\%). Mean age was $53 \pm 13$ years, mean BMI was $27 \pm 6 \mathrm{~kg} / \mathrm{m}^{2}$. Overall, 180 patients (65\%) complained of any kind of pain. Adrenocorticotropin-secreting pituitary adenomas were most frequently associated with pain $(n=34,76 \%)$, followed by $\mathrm{GH}$-secreting pituitary adenomas $(n=59,73 \%)$.

\section{Tumour characteristics}

For the whole group, 163 of the tumours were macroadenomas (59\%) and 87 were microadenomas (31\%). In 28 patients $(10 \%)$, no data were available on tumour size. Macroadenomas were more common in the NFPA $(83 \%)$ 
and acromegaly groups (65\%), while microadenomas were more frequent in the $\mathrm{CD}(67 \%)$ and prolactinoma groups (51\%; $P=0.000)$. Headache was equally frequent in patients with macroadenomas and patients with microadenomas (68 vs $60 \% ; P=0.266$ ).

\section{Treatment characteristics}

One hundred and eighty-two patients (66\%) underwent transsphenoidal adenomectomy: these patients were not affected more frequently by headache (64 vs $62 \%$; $P=0.787)$. Fifty-one patients (18\%) underwent additional radiotherapy ( $n=19$, stereotactic fractionated; $n=13$, gammaknife; $n=1$, cyberknife; $n=18$, unknown). Overall, 162 (58\%) patients received $\geq 1$ medical therapy, comprising somatostatin analogues $(n=50)$, dopamine agonists $(n=123)$, the GH receptor antagonist $(n=9)$ and adrenostatic compounds $(n=15)$. Demographic, tumour and treatment characteristics as well as comorbidities of the overall study population and according to each tumour subtype are given in Table 1.

\section{Pain characteristics according to GPQ}

Primary pain site $\downarrow$ For the whole group, the most common pain location was the lower back (67\%), followed by the neck (66\%) and the shoulder/arm/hand regions (66\%). Table 2 provides an overview of the primary sites of pain in the different pituitary disorders.

Side shift $~-$ The majority of the pituitary adenoma patients reported no pain side shift (91\%). No side shift was recorded in $98 \%$ of $\mathrm{CD}, 95 \%$ of prolactinoma, $88 \%$ of acromegaly and $85 \%$ of NFPA patients respectively $(P=0.028)$.

Quality - The commonest quality of pain was described as 'deep' ( $n=180,65 \%)$. 'Deep' pain was reported by $62 \%$ of acromegaly, $80 \%$ of CD, $64 \%$ of prolactinoma and $58 \%$ of NFPA patients $(P>0.05)$.

Intensity Regarding pain intensity within the last 4 weeks, pituitary adenoma patients reported on a scale of 0 (=no pain) to 10 (=most severe pain) a mean pain intensity of $4 \pm 2$, the most severe pain intensity as $6 \pm 2$ and the mildest pain intensity as $2 \pm 2$. CD patients reported the most severe pain intensity with $7 \pm 2$, whereas prolactinoma patients reported the mildest pain intensity with $2 \pm 2$.
Frequency and duration - The majority of the overall study population (41\%) complained of episodic pain, while $21 \%$ complained of permanent pain. Permanent pain was most frequent in CD patients (31\%). Only $10 \%$ of the patients described their pain as chronic with pain attacks. Median pain duration was $14 \pm 10$ years. Pain side shift, quality, intensity and frequency amongst tumour subtypes are presented in Table 2.

\section{Associated features}

The commonest associated symptoms comprised visual disturbances (28\%), noise sensitivity (19\%), nausea (19\%) and photophobia (18\%). Indeed, pain was accompanied by visual disturbances in 25, 27 and $28 \%$ of the acromegaly, prolactinoma and NFPA patients respectively, whereas CD patients most frequently associated pain to photophobia (29\%). Fifteen percent of the photophobic CD patients suffered neither from headache nor from pain of the neck region.

\section{Trigger factors}

Physical stress appeared to trigger pain in $41 \%$ of the pituitary adenoma patients, followed by emotional stress (21\%) and other causes (16\%).

\section{Alleviating factors}

Non-pharmacological alleviating factors included 'resting' (44\%) and the use of motion/exercise (25\%).

\section{Family history}

The majority of the pituitary adenoma patients (86\%) had no family history of a pain disorder (acromegaly, 83\%; CD, 84\%; prolactinoma, 84\%, NFPA, 93\%) (P>0.05). Pain associated features, trigger factors, alleviating factors and family history within the study population are given in Table 3 .

\section{Headache-related disability (according to MIDAS)}

According to MIDAS, the majority of the patients (72\%) presented with little or no headache-related disability (Grade I) on daily life. Within the subgroups, 73\% of the acromegalic, $63 \%$ of the $\mathrm{CD}, 72 \%$ of the prolactinoma and $70 \%$ of the NFPA subjects had little or no headache-related disability. However, 25\% of the CD population reported severe headache-related disability (Grade IV). Distribution of MIDAS scores in the overall study population and according to each tumour subtype is shown in Fig. 1. 


\begin{tabular}{|c|c|c|c|}
\hline 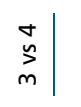 & $\frac{8}{8}: \%$ & $\frac{8}{8}$ &  \\
\hline 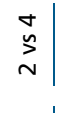 & 亏ั & 亏ั & 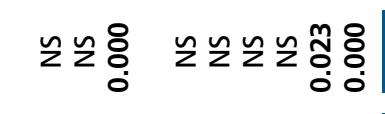 \\
\hline$\stackrel{m}{\sim}$ & $\approx 2$ & $\underline{z}$ & 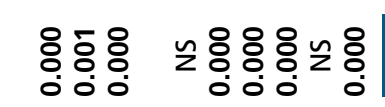 \\
\hline$\underline{m}$ & 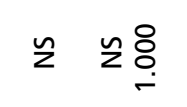 & n & 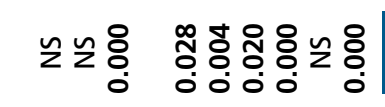 \\
\hline & $\tilde{z}$ & 영 & ¿.: \\
\hline & 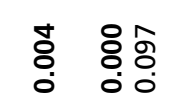 & ః &  \\
\hline
\end{tabular}

융 :

$\infty$ เก่ เก

8

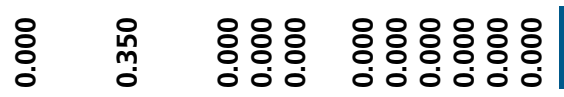

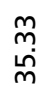

กึ in ì

மீர

Nㅗㅀㅇㅔ



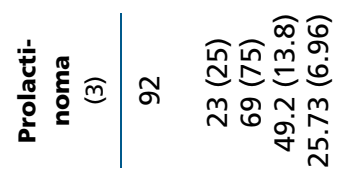



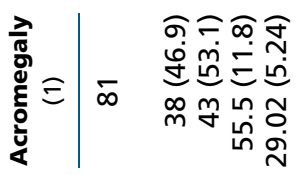



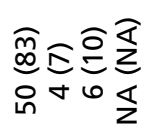

ลิ จุ

过远产递

守용

ติธ

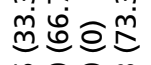

느잉 $\mathrm{m}$

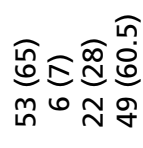

อิกิน

禹商它

กำ $\stackrel{\infty}{\sim}$ ₹

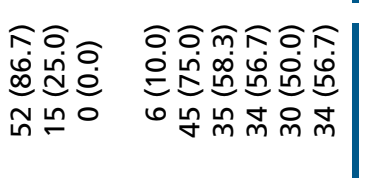

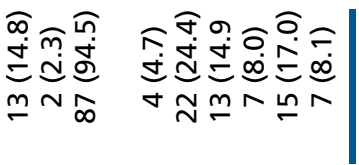

कิิก

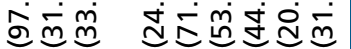

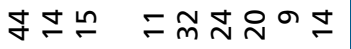

วละ ลิกลชช

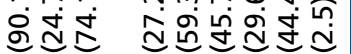

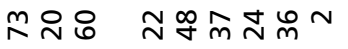

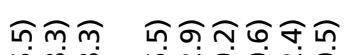

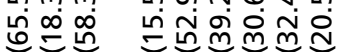

든 







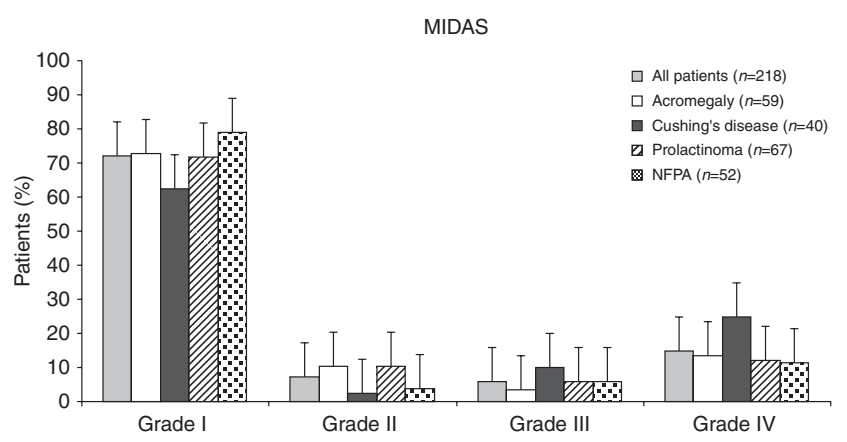

Figure 1

Distribution of migraine disability assessment (MIDAS) scores amongst tumour types and for the group as a whole.

The highest MIDAS scores were recorded in the CD and NFPA patient group ( $20 \pm 40$ and $12 \pm 38$ respectively). The mean MIDAS score for the whole group was $12 \pm$ 33 days.

\section{Neuropathic vs nociceptive pain (according to painDETECT)}

The majority of the patients fulfilled screening criteria for a nociceptive pain component (80\%), followed by uncertain pain $(11 \%)$ and a neuropathic pain component (1\%). Within the subgroups, $84 \%$ of the acromegalic, $78 \%$ of the $\mathrm{CD}, 72 \%$ of the prolactinoma and $88 \%$ of the NFPA subjects complained of nociceptive pain (Fig. 2).

The highest mean painDETECT scores were seen in the prolactinoma and CD patient group $(9 \pm 8$ and $8 \pm 7$ respectively). Mean painDETECT score for the whole group was $7 \pm 7$.

\section{Impact of modifiable factors}

Patients with hormonal hypersecretion independent of tumour type differed significantly from patients with biochemically controlled pituitary disease regarding the painDETECT score $(P=0.007)$. Other modifiable factors including tumour size, genetic predisposition, previous surgery, irradiation or medical therapy did not have a significant impact on headache-related disability (MIDAS score) or neuropathic pain components (painDETECT score; data not shown).

\section{Correlation with depression and QoL}

Table 4 shows the Pearson's $r$ correlation coefficients between neuropathic pain components (painDETECT) and headache-related disability (MIDAS) with depression
(BDI) and health-related QoL (visual analogue scale EQ-VAS) in all 278 patients and within the subgroups.

There was statistical significance in all correlations between neuropathic pain, depression and impaired health-related QoL $(P<0.05)$. Regarding headache-related disability, there was again statistical significance in nearly all correlations with depression, with the exception of acromegalic $(P=0.412)$ and prolactinoma patients $(P=0.315)$ and with health-related QoL with the exception of NFPA patients $(P=0.127)$.

\section{Discussion}

The aim of this study was to investigate the clinical characteristics of pain in pituitary disease. To our knowledge, this is the first study to examine bodily pain and headache in a large cohort of patients with pituitary adenomas.

The main findings of our study are as follows: i) there is a high prevalence of bodily pain in patients with pituitary adenomas independent of the tumour type; ii) patients with $\mathrm{CD}$ seem to be especially susceptible to pain, compared with the other patient groups; iii) the majority of the pituitary patients suffer from a nociceptive pain component; (iv) we recorded a high incidence of headache independent of tumour type; however, the majority of the study population reported little or no headache-related disability in everyday life; (v) modifiable factors including tumour size, genetic predisposition, previous surgery, irradiation or medical therapy do not seem to have a significant impact on pain; and (vi) pain and pain-related disability correlated significantly with depression and impaired QoL.

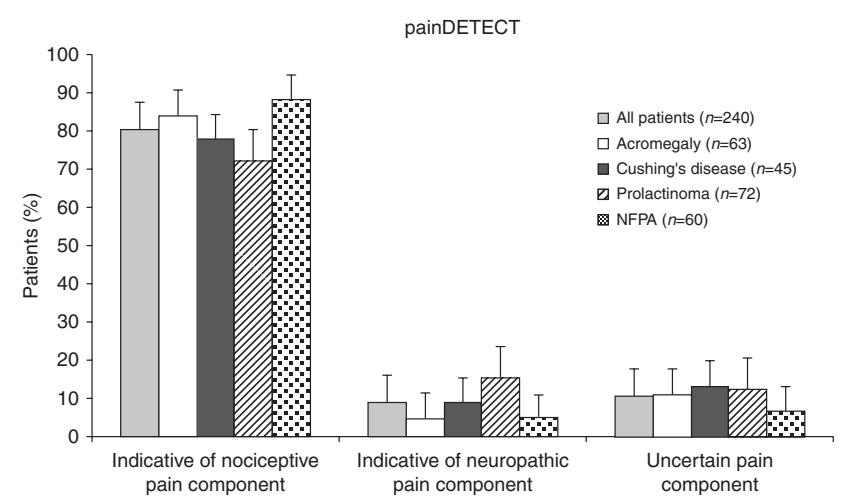

Figure 2

Distribution of painDETECT scores amongst tumour types and for the group as a whole. 
Table 4 Correlation of pain with quality of life (QoL) and depression. Significant effects are in bold face.

\begin{tabular}{|c|c|c|c|c|}
\hline & \multicolumn{2}{|c|}{ BDI } & \multicolumn{2}{|c|}{ EQ-VAS } \\
\hline & $r$ & $P$-value & $r$ & $P$-value \\
\hline \multicolumn{5}{|l|}{ painDETECT } \\
\hline Total & 0.431 & 0.000 & -0.415 & 0.000 \\
\hline Acromegaly & 0.318 & 0.011 & -0.342 & 0.007 \\
\hline Cushing's disease & 0.719 & 0.000 & -0.577 & 0.000 \\
\hline Prolactinoma & 0.528 & 0.000 & -0.479 & 0.000 \\
\hline NFPA & 0.327 & 0.011 & -0.283 & 0.031 \\
\hline \multicolumn{5}{|l|}{ MIDAS } \\
\hline Total & 0.290 & 0.009 & -0.412 & 0.000 \\
\hline Acromegaly & 0.109 & NS & -0.451 & 0.000 \\
\hline Cushing's disease & 0.420 & 0.007 & -0.347 & 0.030 \\
\hline Prolactinoma & 0.126 & NS & -0.265 & 0.036 \\
\hline NFPA & 0.460 & 0.001 & -0.216 & NS \\
\hline
\end{tabular}

BDI, Beck Depression Inventory; EQ-VAS, EQ visual analogue scale of the EuroQOL questionnaire; MIDAS, migraine disability assessment; $r$, Pearson's correlation coefficient; NFPA, non-functioning pituitary adenoma; NS, not significant.

Patients with pituitary adenomas suffer frequently from bodily pain; however, the causal connection between bodily pain and pituitary disease is not clear. For acromegaly, we know that persistent GH excess can lead to arthropathy and arthralgia (5). On the other hand, PRL has been involved in the development of pain disorders via modulation of the transient receptor potential vanilloid type 1 (27). Notably, NFPA patients lacking hormone excess presented a comparable pain profile as patients with other pituitary entities, underlying the importance of the pituitary mass per se.

We found that CD patients are more prone to develop pain, which is not surprising, since hypothalamo-pituitary-adrenal axis dysfunction has been suggested as a contributing factor to the development of chronic pain both in animal models and clinical studies (6). Recent studies have identified cortisol as a positive predictor of pain sensitivity (28). Cortisol levels correlate negatively with pain thresholds during stress (29), potentially explaining the high incidence of pain in CD.

According to painDETECT, patients with pituitary disease are affected by nociceptive rather than neuropathic pain components. As nociceptive pain is caused by stimulation of peripheral nerve fibres that respond to stimuli approaching or exceeding the intensity threshold of nociceptors, musculo-skeletal abnormalities and/or a state of low-grade chronic inflammation in hormone excess syndromes e.g. CD might play a role in pain pathogenesis in these patients. However, this finding needs to be considered with caution, as no physicianbased confirmation of neuropathic vs nociceptive pain was obtained in our study and the painDETECT questionnaire has been designed for screening rather than definite diagnosis (30). Moreover, the finding of more nociceptive than neuropathic pain is somewhat contradictory to previous results on pain mechanisms in patients with pituitary adenomas (polyneuropathy and compression neuropathies due to median nerve oedema in acromegaly (31) and peripheral neuropathies due to high incidence of diabetes mellitus in CD (32)).

Regarding the incidence of headache in our study, these results fall at the higher end of published rates for patients with pituitary adenomas so far (38-70\%) (1). Initially, we attributed this finding to the high ratio of macroadenomas in our group: however, this could not be confirmed by further analysis. Mechanical/compressive explanations in the pathogenesis of headache are not supported in the literature and the association between tumour size and headache remains unclear (33). Interestingly, headache did not induce significant disability in everyday life of most patients, probably because of its episodic nature. The average MIDAS score for the whole group was 12, indicating moderate disability and comparing to scores as high as 96 being reported e.g. in refractory migraine (34). In general, headache-related disability appeared to be somewhat lower in functional than non-functional pituitary disease.

The effect of local/mechanical modifiable factors such as tumour size, previous surgery and irradiation or systemic factors, e.g. genetic predisposition, hormonal hypersecretion and medical therapy, was previously investigated only regarding its relationship with headache in patients with pituitary adenomas. Regarding bodily pain, we anticipated a lacking influence of local/mechanical factors on examined pain features. Nonetheless, neither systemic parameters such as medical therapy and hormonal hypersecretion (significant effect only on painDETECT score) had significant impact on pain, suggesting previous irreversible effects on the CNS leading to chronic pain. This contradicts previous findings, especially in patients with prolactinoma and acromegaly, showing positive correlation between headache and circulating PRL levels or GH excess respectively $(35,36)$.

Finally, we showed that pain and pain-related disability correlated with depression and impaired QoL. As depression is treatable and the relation between pain and depression is likely bi-directional, treatment of depressive symptoms may likely improve the overall QoL of affected patients.

As a weakness of this study we have to consider, next to its cross-sectional design, the fact that there was no 
register-based age- and gender-matched control group, which could account for pain and headache suffering in a matched population. However, as the aim of the study was to emphasise the possible role of hormonal hypersecretion in patients with pituitary adenomas, we contrasted with a clinical control group of patients with NFPA, instead of normal population controls. We believe that this study design is justifiable and should be sufficient to give a reliable picture of pain characteristics in patients with pituitary adenomas.

Picking up the pain problem is relatively straight forward when a cautious history is taken and when one specifically addresses pain as a potential symptom. Whether this is performed by using structured questionnaires (e.g. current study) or in a less structured way is of minor importance, as long as pain is not neglected. In a proportion of patients, a referral to specialist pain assessment and treatment (e.g. by orthopedic surgeons, anesthesiologists, neurologists) may be useful, but this needs to be determined on a case-by-case basis, and no general recommendations can be given in our view. The other way around, pain specialists should be alert for pituitary tumours when looking for secondary headache causes mimicking, e.g. cluster headache, and express promptly clinical suspicion of a pituitary adenoma in respective headache or pain patients.

\section{Conclusions}

Pain appears to be a significant problem in pituitary disease associated with a range of pain phenotypes. Pain syndromes seem to persist even after long-term biochemical cure of the pituitary disease. As a clinical recommendation, we believe that the assessment of pain should be integrated in the diagnostic work-up and followup of patients with pituitary disease. In this context, the interrelation between pain and affective symptoms should also be taken into account.

Regarding treatment, affected patients can be difficult to treat. The best strategy is certainly to identify patients with symptoms suggestive of pituitary adenoma early and treat them causally. This may prevent or slow the development of pain symptoms, at least in a subgroup of patients (e.g. arthropathy and arthralgia in acromegaly). Once the pain problem has fully developed, multimodal treatment strategies are often necessary (optimisation of endocrinological treatment, pharmaceutical pain management, physiotherapy, behavioural psychotherapy when appropriate etc.).

\section{Declaration of interest}

C Dimopoulou received lecture fees from Pfizer and Novartis. A P Athanasoulia received an independent research grant and lectures fees from Pfizer. E Hanisch and S Held have nothing to disclose. T Sprenger has received no personal compensation. His employer, the University Hospital Basel, has received compensation for his serving on scientific advisory boards or speaking fees from Novartis, ATI, Genzyme, Actelion, Jansen, Teva, Mitsubishi Pharma Europe and Biogen Idec. These funds were used for research. T R Toelle received lecture fees from Grünenthal, Mundipharma, Lilly, Pfizer. J Roemmler-Zehrer received research grants from Pfizer and Ipsen, travel grants from Pfizer, Novartis and Lilly as well as lecture fees from Novartis. J Schopohl received lecture fees from Pfizer, Ipsen and Novartis. G K Stalla received lecture fees from Pfizer, Novo Nordisk, Ipsen and Novartis. C Sievers and G K Stalla received an independent research grant from Pfizer.

\section{Funding}

NeoExNET (Network of Excellence for Neuroendocrine Tumours) is a national database for the evaluation of diagnostics, treatment and outcome in neuroendocrine tumours. NeoExNET is supported by the German Federal Ministry of Education and Research (BMBF; m4 Cluster, 16EX1221J, 01EX1020E) and by an unrestricted educational grant of Novartis. Members of the NeoExNET-Study group include: Principal investigator: G K Stalla (MPI of Psychiatry, Munich). Steering Committee: Felix Beuschlein (LMU, Munich), Christoph Auernhammer (LMU, Munich), Klaus A Kuhn (TU, Munich). This project was partly funded by an Else Kröner-Fresenius grant (2012_A103).

\section{References}

1 Kreitschmann-Andermahr I, Siegel S, Weber Carneiro R, Maubach JM, Harbeck B \& Brabant G. Headache and pituitary disease: a systematic review. Clinical Endocrinology 201379 760-769. (doi:10.1111/cen. 12314)

2 Levy MJ. The association of pituitary tumors and headache. Current Neurology and Neuroscience Reports 201111 164-170. (doi:10.1007/ s11910-010-0166-7)

3 Fleseriu M, Yedinak C, Campbell C \& Delashaw JB. Significant headache improvement after transsphenoidal surgery in patients with small sellar lesions. Journal of Neurosurgery $2009110354-358$. (doi:10.3171/2008.8. JNS08805)

4 Levy MJ, Matharu MS, Meeran K, Powell M \& Goadsby PJ. The clinical characteristics of headache in patients with pituitary tumours. Brain 2005128 1921-1930. (doi:10.1093/brain/awh525)

5 Biermasz NR, Pereira AM, Smit JW, Romijn JA \& Roelfsema F. Morbidity after long-term remission for acromegaly: persisting joint-related complaints cause reduced quality of life. Journal of Clinical Endocrinology and Metabolism 200590 2731-2739. (doi:10.1210/jc.2004-2297)

6 Alexander JK, DeVries AC, Kigerl KA, Dahlman JM \& Popovich PG. Stress exacerbates neuropathic pain via glucocorticoid and NMDA receptor activation. Brain, Behavior, and Immunity 200923 851-860. (doi:10.1016/j.bbi.2009.04.001)

7 Bair MJ, Wu J, Damush TM, Sutherland JM \& Kroenke K. Association of depression and anxiety alone and in combination with chronic musculoskeletal pain in primary care patients. Psychosomatic Medicine 200870 890-897. (doi:10.1097/PSY.0b013e318185c510)

8 Dimopoulou C, Ising M, Pfister H, Schopohl J, Stalla GK \& Sievers C. Increased prevalence of anxiety-associated personality traits in patients with Cushing's disease: a cross-sectional study. Neuroendocrinology 2013 97 139-145. (doi:10.1159/000338408) 
9 Pereira AM, Tiemensma J \& Romijn JA. Neuropsychiatric disorders in Cushing's syndrome. Neuroendocrinology 201092 (Suppl 1) 65-70. (doi:10.1159/000314317)

10 Sievers C, Dimopoulou C, Pfister H, Lieb R, Steffin B, Roemmler J, Schopohl J, Mueller M, Schneider HJ, Ising M et al. Prevalence of mental disorders in acromegaly: a cross-sectional study in 81 acromegalic patients. Clinical Endocrinology 200971 691-701. (doi:10.1111/j.13652265.2009.03555.x)

11 Athanasoulia AP, Ising M, Pfister H, Mantzoros CS, Stalla GK \& Sievers C. Distinct dopaminergic personality patterns in patients with prolactinomas: a comparison with nonfunctioning pituitary adenoma patients and age- and gender-matched controls. Neuroendocrinology 201296 204-211. (doi:10.1159/000335996)

12 Sievers C, Ising M, Pfister H, Dimopoulou C, Schneider HJ, Roemmler J, Schopohl J \& Stalla GK. Personality in patients with pituitary adenomas is characterized by increased anxiety-related traits: comparison of 70 acromegalic patients with patients with non-functioning pituitary adenomas and age- and gender-matched controls. European Journal of Endocrinology 2009160 367-373. (doi:10.1530/EJE-08-0896)

13 van der Klaauw AA, Kars M, Biermasz NR, Roelfsema F, Dekkers OM, Corssmit EP, van Aken MO, Havekes B, Pereira AM, Pijl H et al. Diseasespecific impairments in quality of life during long-term follow-up of patients with different pituitary adenomas. Clinical Endocrinology 2008 69 775-784. (doi:10.1111/j.1365-2265.2008.03288.x)

14 Biermasz NR, van Thiel SW, Pereira AM, Hoftijzer HC, van Hemert AM, Smit JW, Romijn JA \& Roelfsema F. Decreased quality of life in patients with acromegaly despite long-term cure of growth hormone excess. Journal of Clinical Endocrinology and Metabolism 200489 5369-5376. (doi:10.1210/jc.2004-0669)

15 van Aken MO, Pereira AM, Biermasz NR, van Thiel SW, Hoftiizer HC, Smit JW, Roelfsema F, Lamberts SW \& Romijn JA. Quality of life in patients after long-term biochemical cure of Cushing's disease. Journal of Clinical Endocrinology and Metabolism 200590 3279-3286. (doi:10.1210/jc.2004-1375)

16 Kars M, van der Klaauw AA, Onstein CS, Pereira AM \& Romijn JA. Quality of life is decreased in female patients treated for microprolactinoma. European Journal of Endocrinology 2007 157 133-139. (doi:10.1530/EJE-07-0259)

17 Cesar de Oliveira Naliato E, Dutra Violante AH, Caldas D, Lamounier Filho A, Rezende Loureiro C, Fontes R, Schrank Y, Gomes de Souza R, Vaisman M, Guerra E et al. Quality of life in women with microprolactinoma treated with dopamine agonists. Pituitary $2008 \mathbf{1 1}$ 247-254. (doi:10.1007/s11102-008-0091-9)

18 Nagel B, Gerbershagen HU, Lindena G \& Pfingsten M. Development and evaluation of the multidimensional German pain questionnaire. Schmerztherapeutische Kolloquium 200216 263-270. (doi:10.1007/ s00482-002-0162-1)

19 Alkan H, Ardic F, Erdogan C, Sahin F, Sarsan A \& Findikoglu G. Turkish version of the painDETECT questionnaire in the assessment of neuropathic pain: a validity and reliability study. Pain Medicine 201314 1933-1943. (doi:10.1111/pme.12222)

20 Matsubayashi Y, Takeshita K, Sumitani M, Oshima Y, Tonosu J, Kato S, Ohya J, Oichi T, Okamoto N \& Tanaka S. Validity and reliability of the Japanese version of the painDETECT questionnaire: a multicenter observational study. PLoS ONE 20138 e68013. (doi:10.1371/journal. pone.0068013)

21 Stewart WF, Lipton RB, Kolodner KB, Sawyer J, Lee C \& Liberman JN. Validity of the migraine disability assessment (MIDAS) score in comparison to a diary-based measure in a population sample of migraine sufferers. Pain 200088 41-52. (doi:10.1016/S03043959(00)00305-5)

22 Rabin R \& de Charro F. EQ-5D: a measure of health status from the EuroQol Group. Annals of Medicine 200133 337-343. (doi:10.3109/ 07853890109002087)

23 Beck AT, Ward CH, Mendelson M, Mock J \& Erbaugh J. An inventory for measuring depression. Archives of General Psychiatry 19614 561-571. (doi:10.1001/archpsyc.1961.01710120031004)

24 Beck AT, Steer RA \& Carbin MG. Psychometric properties of the Beck Depression Inventory Twenty-five years of evaluation. Clinical Psychology 19888 77-100. (doi:10.1016/0272-7358(88)90050-5)

25 Giustina A, Barkan A, Casanueva FF, Cavagnini F, Frohman L, Ho K, Veldhuis J, Wass J, Von Werder K \& Melmed S. Criteria for cure of acromegaly: a consensus statement. Journal of Clinical Endocrinology and Metabolism 200085 526-529. (doi:10.1210/jcem.85.2.6363)

26 Nieman LK, Biller BM, Findling JW, Newell-Price J, Savage MO, Stewart PM \& Montori VM. The diagnosis of Cushing's syndrome: an Endocrine Society Clinical Practice Guideline. Journal of Clinical Endocrinology and Metabolism 200893 1526-1540. (doi:10.1210/ jc.2008-0125)

27 Diogenes A, Patwardhan AM, Jeske NA, Ruparel NB, Goffin V, Akopian AN \& Hargreaves KM. Prolactin modulates TRPV1 in female rat trigeminal sensory neurons. Journal of Neuroscience $2006 \mathbf{2 6} 8126-8136$. (doi:10.1523/JNEUROSCI.0793-06.2006)

28 Lacourt TE, Houtveen JH, Doornen LJ, Benson S, Grigoleit JS, Cesko E \& Elsenbruch S. Biological and psychological predictors of visceral pain sensitivity in healthy premenopausal women. European Journal of Pain 201418 567-574. (doi:10.1002/j.1532-2149.2013.00397.x)

29 Choi JC, Chung MI \& Lee YD. Modulation of pain sensation by stressrelated testosterone and cortisol. Anaesthesia 201267 1146-1151. (doi:10.1111/j.1365-2044.2012.07267.x)

30 Freynhagen R, Baron R, Gockel U \& Tolle TR. painDETECT: a new screening questionnaire to identify neuropathic components in patients with back pain. Current Medical Research and Opinion 200622 1911-1920. (doi:10.1185/030079906X132488)

31 Chanson P, Salenave S, Kamenicky P, Cazabat L \& Young J. Pituitary tumours: acromegaly. Best Practice \& Research. Clinical Endocrinology \& Metabolism 200923 555-574. (doi:10.1016/j.beem.2009.05.010)

32 Pivonello R, De Martino MC, De Leo M, Tauchmanova L, Faggiano A, Lombardi G \& Colao A. Cushing's syndrome: aftermath of the cure. Arquivos Brasileiros de Endocrinologia e Metabologia 200751 1381-1391. (doi:10.1590/S0004-27302007000800025)

33 Levy MJ, Jager HR, Powell M, Matharu MS, Meeran K \& Goadsby PJ. Pituitary volume and headache: size is not everything. Archives of Neurology 200461 721-725. (doi:10.1001/archneur.61.5.721)

34 Irimia P, Palma JA, Fernandez-Torron R \& Martinez-Vila E. Refractory migraine in a headache clinic population. BMC Neurology 20111194. (doi:10.1186/1471-2377-11-94)

35 Arafah BM, Prunty D, Ybarra J, Hlavin ML \& Selman WR. The dominant role of increased intrasellar pressure in the pathogenesis of hypopituitarism, hyperprolactinemia, and headaches in patients with pituitary adenomas. Journal of Clinical Endocrinology and Metabolism 200085 1789-1793. (doi:10.1210/jcem.85.5.6611)

36 Marzocchi N, Cainazzo MM, Catellani D \& Pini LA. A case of a GH-producing pituitary adenoma associated with a unilateral headache with autonomic signs. Journal of Headache and Pain 20056 152-155. (doi:10.1007/s10194-005-0170-5)

Received 10 May 2014

Revised version received 1 August 2014

Accepted 6 August 2014 